\title{
Green Technology, Cloud Computing and Data Centers: the Need for Integrated Energy Efficiency Framework and Effective Metric
}

\author{
Nader Nada \\ Fatih University \\ Istanbul, Turkey
}

\author{
Abusfian Elgelany \\ Sudan University \\ Khartoum, Sudan
}

\begin{abstract}
Energy efficiency (EE), energy consumption cost and environmental impact are vibrant challenges to cloud computing and data centers. Reducing energy consumption and emissions of carbon dioxide $\left(\mathrm{CO}_{2}\right)$ in data centers represent open areas and driving force for future research work on green data centers. Our Literature review reveals that there are currently several energy efficiency frameworks for data centers which combine a green IT architecture with specific activities and procedures that led to decrease the impact on environment and less $\mathrm{CO}_{2}$ emissions. The current available frameworks have some pros and cons that is the reason why there is an urgent need for an integrated criterion for selecting and adopting energy efficiency framework for data centers. The required energy efficiency framework criteria should also consider the social network applications as a vital related factor in elevating energy consumption, as well as high potential for better energy efficiency in data centers. Additionally, in this paper, we highlighted the importance of the identification of efficient and effective energy efficiency metric that can be used for the measurement and determination of the value of data centers efficiency and their performance combined with sound and empirically validated integrated EE framework.
\end{abstract}

Keywords-Cloud Computing; green Cloud; Datacenter; Energy efficiency

\section{InTRODUCTION To GREEN TECHNOLOGY IN ClOUd COMPUTING}

Cloud computing is a promising area in distributed computing. Data centers are the main component of cloud computing. Data centers energy consumption cost and environmental effect are dynamic challenge to cloud computing. Additionally, the growing usage of social applications and the expansion of e-business require an increase in the number of data centers. However, the combination of global warming and inconsistent climate make the cost of energy a major challenge for the sustainability of ebusiness [1]. It is a corner stone of the infrastructure of cloud computing approach by which a variety of information technology (IT) services were built. They extended the ability of centralized repository for computing, hosting, storage, management, monitoring, networking and deployment of data.
With the rapid increase in the capacity and size of data centers, there is a continuous increase in the demand of energy consumption [2]. Data centers, beside their ongoing high energy consumption, also produce carbon dioxide that riddled with IT inefficiencies. International Data Corporation (IDC) annual report found that cloud computing reached $\$ 42 \mathrm{bn}$ in 2012 and the revenue of cloud in 2013 was \$150bn [3].

Environmental impact of Information Technology (IT) under the banner of "Green IT" was been discussed by academia, media and government Since (2007), when the Environmental Protection Agency (EPA) submitted a report to the US Congress [5] about the expected energy consumption of data centers. Since then Green IT has been receiving growing attention. The overall objective of Green IT is to increase energy efficiency and reduce $\mathrm{CO}_{2}$ emissions [6], figure 1 represents the effect of good practice of green data centers to gas emission. There are two ways to make data center greener: First, improve energy efficiency of data center, second, use clean energy supply. Cloud computing has different techniques to solve energy-efficient problem by minimizing the impact of cloud computing on the environment. These techniques deal with energy efficiency consumption like virtualization, hardware base, operating systems base and data centers. Some new features arise like energy performance, and time wise. However, the concerns should be to swap problem between energy consumption and performance.

\section{LITERATURE REVIEW ON ENERGY EFFICIENCY FRAMEWORKS FOR CLOUD COMPUTING}

In our literature review below is based on previous studies of investigated energy efficiency on cloud computing and focused on data center technology.

Asghar Sabbaghiet al.[9], investigated previous researches and introduced energy efficiency framework on information technology that enabled Green supply chain management. They proposed a unique conceptual taxonomy of information technology for sustainability. They also identified the relationship between Green supply chain management information flow, IT governance and Green infrastructure components. 


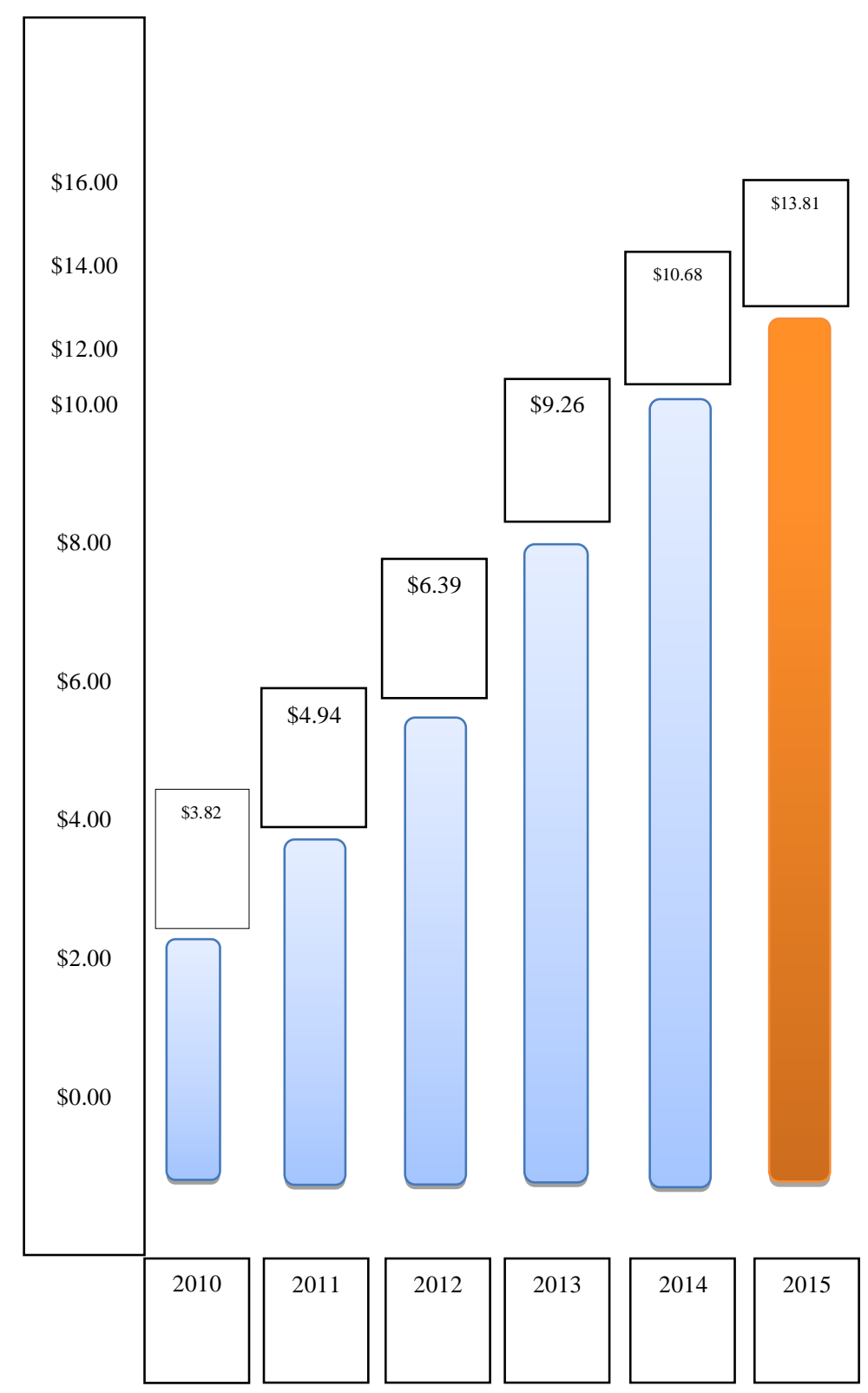

Fig. 1. Green Data Center Market Value [7]

Zhiming Wang et al.[10], proposed mechanism to support maximizing resource utilization by using active and idle energy consumption by finish time minimization. This mechanism reduces the power consumption by allowing spare servers to be in idle state. This mechanism put into account QoS of cloud datacenter.

RajkumarBuyya et al.[11], proposed a novel mechanism in three ways: (a) architectural principles for energy-efficient management of Clouds; (b) energy-efficient resource allocation policies and scheduling algorithms considering QoS, and devices power usage characteristics; and (c) a novel software technology for energy-efficient management of Clouds.
Anton Beloglazov et al.[12], developed a unique mechanism which supports dynamic consolidation of VMs based on adaptive utilization thresholds, which put into account Service Level Agreements (SLA).

Nguyen Quang Hung et al.[13], proposed unique server selection policy, and four algorithms solving the lease scheduling problem. This approach reduces $7.24 \%$ and $7.42 \%$ energy consumption than the existing greedy mapping algorithm.

Uddin et al.[14]and his team introduced a unique framework to improve the performance and energy efficiency of data centers. They developed a classification mechanism for data center components depending on different resource pools and different parameters like energy consumption, resource utilization, workload, etc. The framework highlights the importance of implementing green metrics like Power Usage Effectiveness (PUE) to measure the efficiency of data center in terms of energy utilization and carbon dioxide $\left(\mathrm{CO}_{2}\right)$ emissions. The framework is based on virtualization and cloud computing to increase the resource utilization of already installed servers from $10 \%$ to more than $50 \%$.

Meenakshi Sharma et al.[15],developed a new mechanism with two steps: firstly they developed an analysis of different Virtual Machine(VM) load balancing algorithms, second introduced a new VM load balancing algorithm that has been developed and implemented in Virtual Machine environment of cloud computing in order to achieve better response time and cost.

In S. Kontogiannis et al.[16], the research team developed a unique mechanism called Adaptive Workload Balancing algorithm (AWLB) for cloud datacenter based web systems which deals with agents into two dimensions the web datacenter and web servers. AWLB algorithm also supports protocol specification for signaling purposes among web switch and datacenter nodes and also utilizes other protocols such as SNMP and ICMP for its balancing process. Performance gains are shown from tests of AWLB against known balancing Least Connections (LC) and Least Loaded (LL) algorithms. Table 1 represents the summary of our literature review on cloud computing energy efficiency frameworks and techniques.

\section{URGENT NEED For ENERGY EFFICIENCY INTEGRATED FraMEWORK FOR ClOUd COMPUTING AND DATA CENTERS}

Reducing energy consumption and emissions of carbon dioxide $\left(\mathrm{CO}_{2}\right)$ in data centers represent open challenges and driving the future research work for green data centers. Our Literature review reveals that there is an urgent need for integrated energy efficiency framework for data centers which combines a green IT architecture with specific activities and procedures that led to minimal impact on environment and less $\mathrm{CO}_{2}$ emissions. The required energy efficiency framework should also consider the social network applications as a vital related factor in elevating energy consumption, as well as high potential for energy efficiency. 
TABLE I. DATA CENTERS ENERGY EFFICIENCY TECHNIQUES

\begin{tabular}{|c|c|c|c|c|}
\hline $\begin{array}{l}\mathbf{N} \\
\mathbf{0}\end{array}$ & Author & Approach & Strengths & Limitation \\
\hline 1 & $\begin{array}{l}\text { Asghar } \\
\text { Sabbag } \\
\text { hi }\end{array}$ & $\begin{array}{l}\text { Conceptual } \\
\text { taxonomy of } \\
\text { information } \\
\text { technology }\end{array}$ & $\begin{array}{l}\text { Supply } \\
\text { Management }\end{array}$ & $\begin{array}{l}\text { Focus on } \\
\text { infrastructure } \\
\text { only }\end{array}$ \\
\hline 2 & $\begin{array}{l}\text { Zhimin } \\
\text { g Wang }\end{array}$ & $\begin{array}{l}\text { Maximizing } \\
\text { resource } \\
\text { utilization }\end{array}$ & $\begin{array}{l}\text { Put into } \\
\text { account QoS }\end{array}$ & $\begin{array}{l}\text { Much job } \\
\text { performance } \\
\text { take amount of } \\
\text { time } \\
\text { Sleep-in- } \\
\text { Waking up- } \\
\text { ready. }\end{array}$ \\
\hline 3 & $\begin{array}{l}\text { Rajku } \\
\text { marBu } \\
\text { yya }\end{array}$ & $\begin{array}{l}\text { Resource } \\
\text { allocation } \\
\text { and } \\
\text { scheduling }\end{array}$ & $\begin{array}{l}\text { Quality-of- } \\
\text { service }\end{array}$ & $\begin{array}{l}\text { No parameter to } \\
\text { indicate } \quad \mathrm{CO}_{2} \\
\text { emission }\end{array}$ \\
\hline 4 & $\begin{array}{l}\text { Anton } \\
\text { Belogla } \\
\text { zov }\end{array}$ & $\begin{array}{l}\text { Adaptive } \\
\text { utilization }\end{array}$ & $\begin{array}{l}\text { Meeting the } \\
\text { Service } \\
\text { Level } \\
\text { Agreements } \\
\text { (SLA) }\end{array}$ & $\begin{array}{l}\text { No parameter to } \\
\text { show the } \\
\text { energy } \\
\text { efficiency level }\end{array}$ \\
\hline 5 & $\begin{array}{l}\text { Meena } \\
\text { kshi } \\
\text { Sharma }\end{array}$ & $\begin{array}{l}\text { Load } \\
\text { balancing } \\
\text { algorithms }\end{array}$ & $\begin{array}{l}\text { Good in } \\
\text { reduce } \\
\text { energy, } \\
\text { pricing and } \\
\text { time }\end{array}$ & $\begin{array}{l}\text { Much } \\
\text { calculation need } \\
\text { more time to } \\
\text { take decision }\end{array}$ \\
\hline 6 & $\begin{array}{l}\text { Mueen } \\
\text { Uddin }\end{array}$ & $\begin{array}{l}\text { Virtualizatio } \\
\mathrm{n}\end{array}$ & $\begin{array}{l}\text { Increase the } \\
\text { utilization } \\
\text { ratio }\end{array}$ & $\begin{array}{l}\text { High utilization } \\
\text { leads to } \\
\text { introduce } \mathrm{CO}_{2}\end{array}$ \\
\hline 7 & $\begin{array}{l}\text { S. } \\
\text { Kontog } \\
\text { iannis }\end{array}$ & $\begin{array}{l}\text { workload } \\
\text { balancing } \\
\text { algorithm }\end{array}$ & $\begin{array}{l}\text { can balance } \\
\text { the workload } \\
\text { in } \\
\text { multidimensi } \\
\text { onal } \\
\text { resources }\end{array}$ & $\begin{array}{l}\text { Increase the } \\
\text { Web traffic }\end{array}$ \\
\hline
\end{tabular}

\section{Green Metrics To Measure And Assess Energy EFFICIENCY OF DATA CENTER}

Globally, the energy consumption of data centers is continuously on the increase [17]. The energy operations cost will continue to double every five years between 2005 and 2025 [18]. This increase led to higher emission of $\mathrm{CO}_{2}$ that reflects negatively on global warming and environmental health.

Measuring energy consumption of data centers has become a significant concern of all datacenters stakeholders to meet end-user agreement [19].Energy efficiency metric is a tool used to measure energy efficiency in data centers [20]. The most important challenge in the data centers industry is the limitation of effective standard energy efficiency metrics, which supports improving energy efficiency [21,22].

For an effective energy efficiency assessment on data centers and its components, we need to assess the effectiveness of the used metrics and to measure the energy efficiency of data centers. To determine whether these metrics are effective or not we need to assess these metrics against its intended goals and under a range of common used cases to determine the values of its effectiveness in terms of reporting, targets, education, analysis and decision support [23].
Our literature review on common energy efficiency metrics that are currently in use by data centers reveals that none of these metrics are meeting the prior mentioned criteria. Therefore, our research is not only introducing a comparative review of the most common used metrics and their features (criteria) but also attempting to recommend better metric to be used in the assessment of data centers energy efficiency.

In last few years operators have adopted PUE metrics as the measure of energy efficiency for the mechanical and electrical infrastructure of the data center. The process of assessment has submitted a focus and comparable measure of performance, which has enabled data centers operators to make substantial improvements. However, until now no consensus about IT or software energy efficiency and most energy efficiency measurements stopped at the IT power cord. In this paper we are proposing the Fixed to Variable Energy Ratio (FVER) metric which could be used to measure the data centers energy efficiency instead of PUE. The reason behind our choice in favor of the FVER metric is that it combines and meets all the needed criteria for better energy efficiency assessment in data centers, listed in table 2, including the usage of IT and software applications in data centers [24]. Figure 1 depicts the difference between FVER and PUR and Table 2 represents the different Goals of energy efficiency metrics including PUE, DCiE, FVER, and DCeP where:

$$
\begin{aligned}
& \text { Power Usage Effectiveness (PUE) }= \\
& \text { Total Facility Power/ IT Equipment Power }
\end{aligned}
$$

Data Center Infrastructure Effectiveness $($ DCiE) $=1 /$ PUE (2)

Fixed to Variable Energy Ratio (FVER) $=1+$ Fixed Energy/Variable Energy

Data Center Energy Productivity $(\mathrm{DCeP})=$ Useful Work Produced / Total Data Center Energy Consumed over time (4)

\section{CONCLUSION AND CONTRIBUTION}

The first contribution of this paper is our literature review on current energy efficiency frameworks. The study reveals that there are currently several energy efficiency frameworks for data centers which combine a green IT architecture with specific activities and procedures that will lead to decrease the impact on environment and the diminution of $\mathrm{CO}_{2}$ emissions. The current available frameworks have some pros and cons (see Table 1) that is why there is an urgent need for an integrated energy efficiency framework for data centers and cloud computing. The framework should consider a common and integrated set of criteria. The selection and adoption of such framework should be in accordance with the data center area of application and its surrounding environment.

The second contribution was the literature review on energy efficiency metrics that are currently used for the assessment of energy efficiency in data centers (depicted in Table 2 and Figure 2). This part of our study developed a comparative study of the most commonly used metrics and their features (criteria), additionally we recommended the use of FVER instead of PUE as a better metric for the assessment of data centers energy efficiency which was based on certain required criteria including the usage of IT and software 
applications in data centers. Our future work will focus on the development and empirical validation of an integrated energy efficiency framework for cloud computing and data centers.

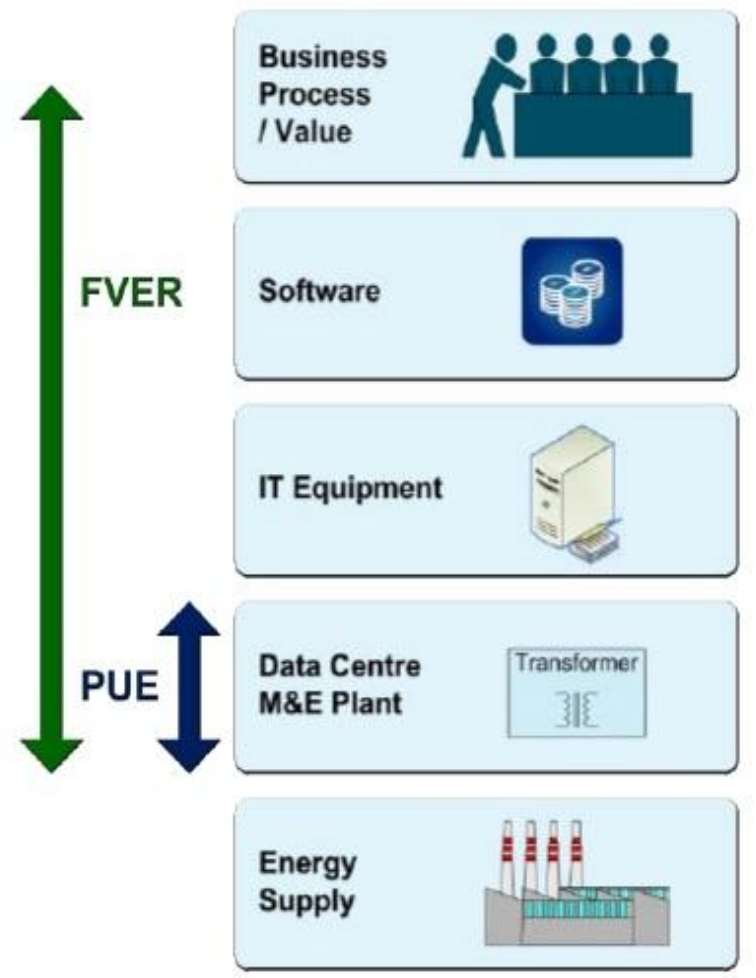

Fig. 2. FVER Vs PUE [25]

\section{REFERENCES}

[1] Mell, P. and T. Grance. The NIST Definition of Cloud Computing, 2009.

[2] Mueen Uddin, framework for energy efficient data centers using virtualization, 2012.

[3] IDC - Press Release, 2013.

[4] Ian Foster, Cloud Computing and Grid Computing 360-Degree Compared, 2008.

[5] James W. Smith, Green Cloud A literature review of Energy-Aware Computing, 2011.

[6] Asghar Sabbaghi, Green Information Technology and Sustainability, 2012.

[7] Ariel Schwartz, Green Data Center Marketto More than TripleOver Next Five Years, 2010.

[8] Eric Woods, Data Center Electricity Consumption 2005-2010: The Good and Bad News, 2011.

[9] Asghar Sabbaghi, Green information technology and sustainability: A Conceptual taxonomy, volume 13, Issue 2, pp. 26-32, 2012.

[10] Zhiming Wang, Energy-aware and revenue-enhancing Combinatorial Scheduling in Virtualized of Cloud Datacenter, Volume7, Number1, January 2012.

[11] Rajkumar Buyya, Energy-Efficient Management of Data Center Resources for Cloud Computing: A Vision, Architectural Elements, and Open Challenges, 2010.

[12] Anton Beloglazov, aSurvey on Power Management Solutions for Individual Systems and Cloud, 2010.

[13] Nguyen Quang Hung, Performance constraint and power-aware allocation for user requests in virtual computing, 2011.
TABLE II. GOALS OF ENERGY EFFICIENCY METRICS [24]

\begin{tabular}{|c|c|c|c|c|c|}
\hline No & Goal & PUE & $\begin{array}{c}\text { DCi } \\
\text { E }\end{array}$ & FVER & DCeP \\
\hline 1 & $\begin{array}{l}\begin{array}{l}\text { Provide a clear, } \\
\text { preferably } \\
\text { understanding } \\
\text { intuitive } \\
\text { measure }\end{array}\end{array}$ & $\mathrm{Y}$ & Y & $\mathrm{Y}$ & \\
\hline 2 & $\begin{array}{lr}\text { Provide } & \text { a clear, } \\
\text { preferably } & \text { intuitive } \\
\text { direction } & \text { of } \\
\text { improvement } & \end{array}$ & & $\mathrm{Y}$ & $\mathrm{Y}$ & $\mathrm{Y}$ \\
\hline 3 & $\begin{array}{l}\text { Describe a clearly } \\
\text { defined part of the } \\
\text { energy to useful work } \\
\text { function of the IT } \\
\text { services }\end{array}$ & & $\mathrm{Y}$ & $\mathrm{Y}$ & $\mathrm{Y}$ \\
\hline 4 & $\begin{array}{l}\text { Be persistent, i.e. the } \\
\text { metrics should be } \\
\text { designed to be stable } \\
\text { and extensible as the } \\
\text { scope of efficiency } \\
\text { measurement increases, } \\
\text { rather than confusing the } \\
\text { market with rapid } \\
\text { replacement }\end{array}$ & Y & $\mathrm{Y}$ & Y & \\
\hline 5 & $\begin{array}{l}\text { Demonstrate the } \\
\text { improvements available } \\
\text { in a modern design of } \\
\text { facility }\end{array}$ & & $\mathrm{Y}$ & $\mathrm{Y}$ & \\
\hline 6 & $\begin{array}{l}\text { Demonstrate the } \\
\text { improvements available } \\
\text { through upgrade of } \\
\text { existing facilities using } \\
\text { more efficient M\&E } \\
\text { systems }\end{array}$ & & $\mathrm{Y}$ & $\mathrm{Y}$ & \\
\hline 7 & $\begin{array}{l}\text { Provide a clear, } \\
\text { preferably intuitive } \\
\text { understanding of the } \\
\text { impacts of changes }\end{array}$ & & & $\mathrm{Y}$ & Y \\
\hline 8 & $\begin{array}{l}\text { Be reversible, i.e. it } \\
\text { should be possible to } \\
\text { determine the energy } \\
\text { use at the electrical input } \\
\text { to the data center for any } \\
\text { specified device or } \\
\text { group of devices within } \\
\text { the data center }\end{array}$ & $\mathrm{Y}$ & & $\mathrm{Y}$ & $\mathrm{Y}$ \\
\hline 9 & $\begin{array}{l}\text { Be capable of } \\
\text { supporting 'what if' } \\
\text { analysis for IT and data } \\
\text { center operators in } \\
\text { determining the energy } \\
\text { improvement and ROI } \\
\text { for improvements and } \\
\text { changes to either the } \\
\text { facility or the IT } \\
\text { equipment it houses }\end{array}$ & $\mathrm{Y}$ & & $\mathrm{Y}$ & \\
\hline
\end{tabular}

[14] Mueen Uddin, Green Information Technology (IT) framework for energy efficient data centers using virtualization, 2012.

[15] Meenakshi Sharma, Performance Evaluation of Adaptive Virtual Machine Load Balancing Algorithm, 2012.

[16] S. Kontogiannis, A probing algorithm with Adaptive workload load balancing capabilities for heterogeneous clusters, journal of computing, volume 3, issue 7, July2011.

[17] Lacity, Mary C and Khan, Shaji A and Willcocks, Leslie P, A review of the IT outsourcing literature: Insights for practice, The Journal of Strategic Information Systems, Elsevier, 18, 130-146 (2009). 
[18] Laura Sisó, Ramon B. Fornós, Assunta Napolitano \&Jaume, Energyand Heat-aware metrics for computing modules, 2012.

[19] Tung, Teresa, Data Center Energy Forecast, Silicon Valley Leadership Group, San Jose, CA, (2008).

[20] Wang, Lizhe and Khan, Samee U, Review of performance metrics for green data centers: a taxonomy study, The Journal of Supercomputing, Springer, 1-18 (2013).

[21] Belady, Christian L and Malone, Christopher G, Metrics and an infrastructure model to evaluate data center efficiency, Proceedings of the Pacific Rim/ASME InternationalElectronic Packaging Technical Conference and Exhibition(IPACK), ASME, (2007).

[22] Rivoire, Suzanne and Shah, Mehul A and Ranganathan, Parthasarathy and Kozyrakis, Christos, JouleSort: a balancedenergy-efficiency benchmark, Proceedings of the 2007 ACMSIGMOD international conference on Management of data,ACM, 365-376 (2007).

[23] Liam Newcombe, Data center energy efficiency metrics existing and proposed metrics to provide effective understanding and reporting of data center energy, 2013.

[24] Liam Newcombe, Data center Fixed to VariableEnergy Ratio metricDCFVER, 2012
[25] Peter Hopton, Move Over PUE, 2012.

[26] G. Eason, B. Noble, and I. N. Sneddon, "On certain integrals of Lipschitz-Hankel type involving products of Bessel functions," Phil. Trans. Roy. Soc. London, vol. A247, pp. 529-551, April 1955. (references)

[27] J. Clerk Maxwell, A Treatise on Electricity and Magnetism, 3rd ed., vol. 2. Oxford: Clarendon, 1892, pp.68-73.

[28] I. S. Jacobs and C. P. Bean, "Fine particles, thin films and exchange anisotropy," in Magnetism, vol. III, G. T. Rado and H. Suhl, Eds. New York: Academic, 1963, pp. 271-350.

[29] K. Elissa, "Title of paper if known," unpublished.

[30] R. Nicole, "Title of paper with only first word capitalized," J. Name Stand. Abbrev., in press.

[31] Y. Yorozu, M. Hirano, K. Oka, and Y. Tagawa, "Electron spectroscopy studies on magneto-optical media and plastic substrate interface," IEEE Transl. J. Magn. Japan, vol. 2, pp. 740-741, August 1987 [Digests 9th Annual Conf. Magnetics Japan, p. 301, 1982].

[32] M. Young, The Technical Writer's Handbook. Mill Valley, CA: University Science, 1989. 